\title{
Influence of recovery mode (passive vs. active) on time spent at maximal oxygen uptake during an intermittent session in young and endurance-trained athletes
}

\author{
Delphine Thevenet · Magaly Tardieu-Berger · \\ Serge Berthoin · Jacques Prioux
}

Accepted: 2 October 2006/ Published online: 7 November 2006

(C) Springer-Verlag 2006

\begin{abstract}
The aim of this study was to analyze the effects of recovery mode (active/passive) on time spent at high percentage of maximal oxygen uptake $\left(V \mathrm{O}_{2 \max }\right)$, i.e. above $90 \%$ of $V \mathrm{O}_{2 \max }\left(t 90 V \mathrm{O}_{2 \max }\right)$ and above $95 \%$ of $V \mathrm{O}_{2 \max }\left(t 95 V \mathrm{O}_{2 \max }\right)$ during a single short intermittent session. Eight endurance-trained male adolescents $(15.9 \pm 1.4$ years $)$ performed three field tests until exhaustion: a graded test to determine their $V \mathrm{O}_{2 \max }$ $\left(57.4 \pm 6.1 \mathrm{ml} \mathrm{min}^{-1} \mathrm{~kg}^{-1}\right)$, and maximal aerobic velocity $\left(\mathrm{MAV} ; 17.9 \pm 0.4 \mathrm{~km} \mathrm{~h}^{-1}\right)$, and in a random order, two intermittent exercises consisting of repeated $30 \mathrm{~s}$ runs at $105 \%$ of MAV alternated with $30 \mathrm{~s}$ passive $\left(\mathrm{IE}_{\mathrm{P}}\right)$ or active recovery $\left(\mathrm{IE}_{\mathrm{A}}, 50 \%\right.$ of MAV). Time to
\end{abstract}

D. Thevenet $(\bowtie) \cdot$ M. Tardieu-Berger

Laboratoire "Motricitè, Interactions,

Performance", (JE n²438), UFR STAPS,

Université de Nantes, Nantes Atlantique Université,

25 bis bd Guy Mollet, BP 72206,

44322 Nantes, Cedex 3, France

e-mail: thevenet.d@gmail.com

D. Thevenet $\cdot$ S. Berthoin

Laboratoire d'Etudes de la Motricité Humaine

(EA n`3608), Faculté des Sciences du Sport et de

l'Education Physique, 9 rue de l'Université,

59790 Ronchin, France

\section{J. Prioux}

Ecole Normale Supérieure (ENS), Cachan,

Antenne de Bretagne, Campus de Ker-Lann,

35170 Bruz, France

\section{J. Prioux}

Laboratoire de Physiologie et de Biomécanique de l'Exercice musculaire (EA n`1274), UFR APS,

Université Rennes 2, Haute Bretagne,

Place du Recteur Henri Le Moal,

35043 Rennes Cedex, France exhaustion $\left(t_{\text {lim }}\right)$ was significantly longer for $\mathrm{IE}_{\mathrm{P}}$ than for $\mathrm{IE}_{\mathrm{A}}(2145 \pm 829$ vs. $1072 \pm 388 \mathrm{~s}, P<0.01)$. No difference was found in $t 90 V \mathrm{O}_{2 \max }$ and $t 95 V \mathrm{O}_{2 \max }$ between $\mathrm{IE}_{\mathrm{P}}(548 \pm 499-316 \pm 360 \mathrm{~s})$ and $\mathrm{IE}_{\mathrm{A}}(746 \pm 417-$ $459 \pm 332 \mathrm{~s})$. However, when expressed as a percentage of $t_{\text {lim }}, t 90 \mathrm{VO}_{2 \max }$ and $t 95 \mathrm{VO} \mathrm{O}_{2 \max }$ were significantly longer $(P<0.001$ and $P<0.05$, respectively) during $\mathrm{IE}_{\mathrm{A}}(67.7 \pm 19 \%-42.1 \pm 27 \%)$ than during $\mathrm{IE}_{\mathrm{P}}$ $(24.2 \pm 19 \%-13.8 \pm 15 \%)$. Our results demonstrated no influence of recovery mode on absolute $t 90 \mathrm{VO}_{2 \max }$ or $t 95 V \mathrm{O}_{2 \max }$ mean values despite significantly longer $t_{\text {lim }}$ values for $\mathrm{IE}_{\mathrm{P}}$ than for $\mathrm{IE}_{\mathrm{A}}$. In conclusion, passive recovery allows a longer running time $\left(t_{\lim }\right)$ for a similar time spent at a high percentage of $V \mathrm{O}_{2 \max }$.

Keywords Intermittent exercise - Recovery mode . Time spent at maximal oxygen uptake . Time to exhaustion · Young athlete

\section{Introduction}

Maximal oxygen uptake $\left(\dot{V} \mathrm{O}_{2 \max }\right)$ is the main variable used in the field of exercise physiology to assess the effects of aerobic training. In training-related studies, increasing $\dot{V} \mathrm{O}_{2 \max }$ of well-trained runners is generally explained by the fact that, during training, exercises allow a high percentage of $\dot{V} \mathrm{O}_{2 \max }\left(90-100 \% \dot{V} \mathrm{O}_{2 \max }\right)$ to be maintained (Fox 1975; Wenger and Bell 1986; Robinson et al. 1991; Tabata et al. 1996; Jones and Carter 2000). Therefore, it can be assumed that the percentage of $\dot{V} \mathrm{O}_{2 \max }$ attained and the time for which it is sustained above $90 \%\left(t 90 \dot{V} \mathrm{O}_{2 \max }\right)$ or $95 \%$ of $\dot{V} \mathrm{O}_{2 \max }\left(t 95 \dot{V} \mathrm{O}_{2 \max }\right)$ could serve as a good criterion to judge the effectiveness of the stimulus. Two exercise 
models could be used to elicit a high percentage of $\dot{V} \mathrm{O}_{2 \max }$ :or even to reach $\dot{V} \mathrm{O}_{2 \max }$ : continuous exercises (Hill and Rowell 1997; Hill et al. 1997) as well as intermittent exercises (IE) (Billat et al. 2000; Dupont et al. 2003a, b; Millet et al. 2003a, b; Tardieu-Berger et al. 2004; Midgley and Naughton 2006). Intermittent exercises have been reported to allow increased total exercise duration $\left(t_{\text {lim }}\right)$ at high intensity (Åstrand et al. (1960) compared with continuous exercises. In a literature review, Midgley and McNaughton (2006) suggested that for high IE $\left(90-105 \%\right.$ of $\left.\dot{V} \mathrm{O}_{2 \max }\right)$ to optimize the time spent at or near $\dot{V} \mathrm{O}_{2 \max }$, and allow an optimal enhancement of $\dot{V} \mathrm{O}_{2 \max }$, the exercise and recovery duration should be between 15 and $30 \mathrm{~s}$. The $30 \mathrm{~s} / 30 \mathrm{~s}$ (30sIE), consisting in $30 \mathrm{~s}$ high intensity exercise alternated with $30 \mathrm{~s}$ active recovery, is commonly practiced by athletes. Åstrand et al. (1960) and Gorostiaga et al. (1991) have shown that a 30sIE realized at $100 \%$ of $\dot{V} \mathrm{O}_{2 \max }$ with a passive recovery, does not allow subjects to elicit $\dot{V} \mathrm{O}_{2 \max }$. Earlier studies (Millet et al. 2003b; Tardieu-Berger et al. 2004) have investigated the 30sIE realized at supra maximal intensity ( 105 or $110 \%$ of $\dot{V} \mathrm{O}_{2 \max }$ ) with active recovery $\left(50 \%\right.$ of $\left.\dot{V} \mathrm{O}_{2 \max }\right)$. These studies showed that adequate combination between exercise and recovery intensities during 30sIE exercises may allow $\dot{V} \mathrm{O}_{2 \max }$ to be reached but also sustained it $\left[t 90 \dot{V} \mathrm{O}_{2 \max }=338 \mathrm{~s}\right.$ (Millet et al. 2003b); $t 95 \dot{V} \mathrm{O}_{2 \max }=178 \mathrm{~s}$ (Tardieu-Berger et al. 2004)]. In these latter studies, the authors focused on the effects of the intensity exercise on $t 90 \dot{V} \mathrm{O}_{2 \max }$ and $t 95 \dot{V} \mathrm{O}_{2 \max }$. However, during an IE, recovery intensity also has an effect on $t 90 \dot{V} \mathrm{O}_{2 \max }$ and $t 95 \dot{V} \mathrm{O}_{2 \max }$. Dupont et al. (2003a, b) during a $15 \mathrm{sIE}$ intermittent exercise $[15 \mathrm{~s}$ at $120 \%$ of maximal aerobic velocity (MAV) alternated with $15 \mathrm{~s}$ recovery] showed that a passive recovery makes it possible to reach $\dot{V} \mathrm{O}_{2 \max }$ and to increase $t_{\text {lim }}$. Currently, the question of an optimal recovery intensity during 30sIE is still an unsolved question. During another high-intensity IE model (around 2 min at $110 \%$ of maximal power output until exhaustion, alternated with $5 \mathrm{~min}$ active at $20 \%$ of $\dot{V} \mathrm{O}_{2 \max }$ or passive recovery repeated four times), Dorado et al. (2004) showed that active recovery enhanced work capacity by increasing the aerobic energy yield compared with passive recovery. Nevertheless, in the latter study, $t 90 \dot{V} \mathrm{O}_{2 \max }$ and $t 95 \dot{V} \mathrm{O}_{2 \max }$ were not calculated. Hence, it is difficult to conclude about the effect of recovery mode on $t 90 \dot{V} \mathrm{O}_{2 \max }$ and $t 95 \dot{V} \mathrm{O}_{2 \max }$ since the protocol in these studies (Dupont et al. 2003a, b; Millet et al. 2003a; Tardieu-Berger et al. 2004) was roughly different. According to Dorado et al. (2004) the increase in aerobic energy yield during IE with active recovery can be explained by the faster $\dot{V} \mathrm{O}_{2}$ kinetics during the high intensity bout preceded by active recovery. This result is in agreement with other studies reporting faster $\dot{V} \mathrm{O}_{2}$ kinetics at the onset of constant intensity exercise when preceded by warm-up (Bangsbo et al. 1994; Geor et al. 2000). The main purpose of this study was therefore to analyze, during a 30sIE, the effects of the recovery mode (active/passive) on $t 90 \dot{V} \mathrm{O}_{2 \max }$ and $t 95 \dot{V} \mathrm{O}_{2 \max }$. More specifically, it was hypothesized that during a 30sIE, active recovery would allow an increase in $t 90 \dot{V} \mathrm{O}_{2 \max }$ and $t 95 \dot{V} \mathrm{O}_{2 \max }$ due to a decrease in time to achieve 90 or $95 \%$ of $\dot{V} \mathrm{O}_{2 \max }$ with active recovery compared with passive recovery. The secondary aim of this study was to improve the knowledge of IE and allow coaches to better prescribe the most effective intermittent session to elicit an optimal solicitation of the aerobic system.

\section{Methods}

Subjects

Eight endurance-trained male adolescents volunteered to participate in this study. The subjects taking part in this study were all from the same athletic club. Within the framework of their training sessions, they regularly practiced the 30sIE with an active recovery at $50 \%$ of MAV. Subjects were from 15 to 18 years old. Their mean \pm standard deviation (SD) for age, mass, and height were $15.9 \pm 1.4$ years, $57.7 \pm 4.8 \mathrm{~kg}$, and $170.6 \pm 4.0 \mathrm{~cm}$, respectively. Prior to participation, they underwent a medical examination and were fully informed of the experimental procedures. Parental consent (for the under-age athletes) and written consent were obtained in accordance with the guidelines of the University of Nantes which had approved the experimental protocol and the procedures involved.

\section{Overview}

All subjects performed three field tests until exhaustion on a 400-m outdoor tartan track (calibrated with cones) at the same time of the day, with at least $48 \mathrm{~h}$ rest between each test. The subjects were required to have their last light meal $3 \mathrm{~h}$ before the tests. All tests were completed within 3 weeks. For each test, the subjects were verbally encouraged to run for as long as possible. Tests were stopped when subjects could not maintain the required speed or when the subjects stopped the exercise, judging themselves exhausted. Before the tests, subjects were familiarized with the 
exercise procedure and with the gas exchange measuring apparatus. Atmospheric conditions were checked before each test ensuring that all sessions were carried out under similar environmental conditions.

Athletes first performed a maximal graded test to determine $\dot{V} \mathrm{O}_{2 \max }$ and MAV. Then, in a random order, they carried out two intermittent exercises consisting of repeating as long as possible $30 \mathrm{~s}$ intensive runs alternating with $30 \mathrm{~s}$ passive recovery $\left(\mathrm{IE}_{\mathrm{P}}\right)$ or active recovery at $50 \%$ of MAV $\left(\mathrm{IE}_{\mathrm{A}}\right)$. All tests were immediately followed by a $12 \mathrm{~min}$ passive rest period. After the rest period, the subject did 5 min continuous jogging, and after 2 min stretching, they were asked to run as long as possible at MAV plus $1 \mathrm{~km} \mathrm{~h}^{-1}$ (MAV +1 test). These tests were performed in order to determine the $\dot{V} \mathrm{O}_{2 \max }$ of the day (Dupont et al. 2003b) and more accurately calculate time spent at $\dot{V} \mathrm{O}_{2 \max }$.

\section{Maximal graded test}

Green cones were set at $25 \mathrm{~m}$ intervals along the track (inside the first line) while red cones were set $2 \mathrm{~m}$ behind the green cones. The running pace was set by an examiner, equipped with a whistle and a chronometer, who made a short sound when the subject had to pass by a cone to be able to maintain a constant speed. A longer sound marked the change in the running stage. At each sound, the subject had to be within $2 \mathrm{~m}$ of the red cones. When subjects were behind a red cone three consecutive times, the test ended. This test was preceded by a warm-up period composed of 10 min continuous jogging, $5 \mathrm{~min}$ of stretching, and five accelerations out of $50 \mathrm{~m}$. The initial speed was 10 $\mathrm{km} \mathrm{h}^{-1}$ and was increased by $1 \mathrm{~km} \mathrm{~h}^{-1}$ every $3 \mathrm{~min}$. This method is in accordance with previous publications (e.g. Billat et al. 1994). Velocity at the last completed stage was considered as MAV. If the velocity at exhaustion was only maintained for 1 min 30 (half of the stage duration), then MAV was considered to be equal to the velocity during the previous stage plus $0.5 \mathrm{~km} \mathrm{~h}^{-1}$ (Kuipers et al. 1985).

\section{Intermittent exercises}

The two intermittent exercises consisted of repeating as long as possible a $30 \mathrm{~s}$ run at $105 \%$ of MAV alternated with $30 \mathrm{~s}$ passive recovery $\left(\mathrm{IE}_{\mathrm{P}}\right.$, Fig. 1a) or active recovery $\left(\mathrm{IE}_{\mathrm{A}}-50 \%\right.$ of MAV; Fig. $\left.1 \mathrm{~b}\right)$. For these exercises, the running pace was given by an examiner making sounds at regular intervals (30 s) up to the end of the exercise. During the $30 \mathrm{~s}$ exercise and the $30 \mathrm{~s}$ active recovery, subjects had to cover a distance determined according by their own MAV. During the recovery period, a longer sound was made at midperiod $(15 \mathrm{~s})$ to inform the athletes of the remaining time for the end of recovery. These two tests were preceded by a standardized warm-up which consisted of $10 \mathrm{~min}$ continuous jogging, followed by $5 \mathrm{~min}$ stretching exercises, and five short bursts of acceleration on the track.

\section{Respiratory gas exchange and heart rate} measurements

During all tests, respiratory gas exchange was measured breath-by-breath using a portable telemetric system [Cosmed $\mathrm{K}_{4} \mathrm{~b}^{2}$, Rome, Italy; (McLaughlin et al. $2001)]$ in order to determine minute ventilation $\left(\dot{V}_{\mathrm{E}}\right)$, tidal volume $\left(V_{\mathrm{T}}\right)$, respiratory frequency $(\mathrm{fr}), \dot{V} \mathrm{O}_{2}$, carbon dioxide output $\left(\dot{V} \mathrm{CO}_{2}\right)$, estimated arterial pressure of $\mathrm{CO}_{2}\left(\mathrm{PaCO}_{2}\right)$ (Wasserman 1994). Before each test and before each MAV +1 test, the $\mathrm{O}_{2}$ and $\mathrm{CO}_{2}$ analysis systems were calibrated using ambient air and a gas of known $\mathrm{O}_{2}$ and $\mathrm{CO}_{2}$ concentrations (16 and $5 \%$, respectively). The calibration of the $\mathrm{K}_{4} \mathrm{~b}^{2}$ turbine flow meter was performed using a 3-1 syringe (Quinton Instruments, Seattle, Washington, USA). Heart rate (HR) was continuously monitored (Polar Electro, Kempele, Finland). The cardio-respiratory values were averaged over a $15 \mathrm{~s}$ period during the maximal graded test and MAV +1 tests, and a $5 \mathrm{~s}$ period for intermittent exercises.

\section{$\dot{V} \mathrm{O}_{2 \max }$ and $\dot{V} \mathrm{O}_{2 \max }$ of the day calculations}

The $\dot{V} \mathrm{O}_{2 \max }$ corresponded to the highest $\dot{V} \mathrm{O}_{2}$ attained in two successive $15 \mathrm{~s}$ periods for the maximal graded test. It was judged that subjects had reached their $\dot{V} \mathrm{O}_{2 \max }$ when three or more of the following criteria were met: (1) a steady state of $\dot{V} \mathrm{O}_{2}$ despite increasing running speed (change in $\dot{V} \mathrm{O}_{2}$ at $\dot{V} \mathrm{O}_{2 \max }$ $\leq 150 \mathrm{ml} \mathrm{min}^{-1}$ ) (Taylor et al. 1955); (2) a final respiratory exchange ratio $\left(R_{\max }\right)$ higher than $1.1 ;$ (3) visible exhaustion; (4) an HR at the end of exercise $\left(\mathrm{HR}_{\max }\right)$ within the $10 \mathrm{bpm}$ of the predicted maximum [210 - $(0.65 \times$ age $) ;($ Spiro 1977) $]$.

The $\dot{V} \mathrm{O}_{2 \text { peak }}$ corresponded to the highest $\dot{V} \mathrm{O}_{2}$ attained in two successive $15 \mathrm{~s}$ periods for the MAV +1 test. It was assumed that the measured $\dot{V} \mathrm{O}_{2 \text { peak }}$ corresponded to the $\dot{V} \mathrm{O}_{2 \max }$ of the day if the duration of the MAV +1 test was at least 2 min (Dupont et al. 2003b). 
Fig. 1 Experimental protocol for (a) $\mathrm{IE}_{\mathrm{P}}$ (intermittent exercise maintained until exhaustion with passive recovery) and (b) $\mathrm{IE}_{\mathrm{A}}$ (intermittent exercise maintained until exhaustion with active recovery $-50 \%$ MAV). Both tests were preceded by the same warmup. MAV: maximal aerobic velocity; $\left[\mathrm{HCO}_{3}^{-}\right]$: bicarbonate ion concentration
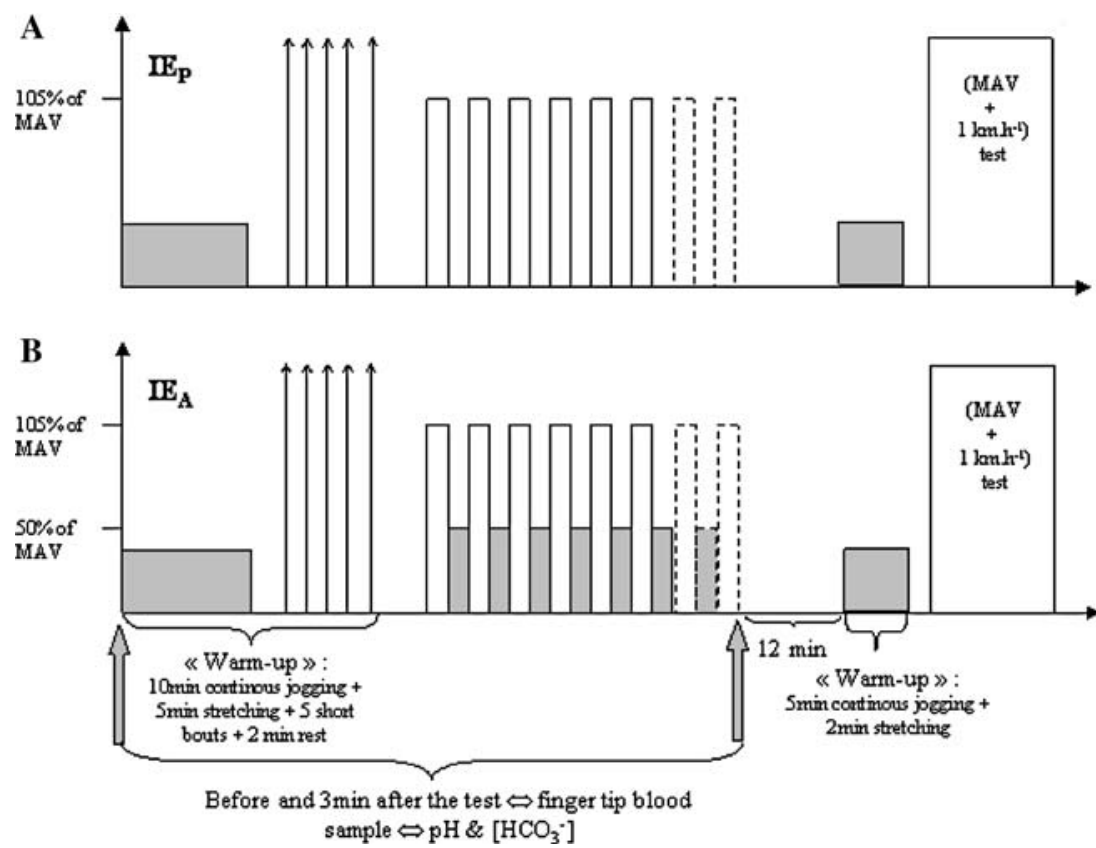

Time to exhaustion, time spent above 90 or $95 \%$ of $\dot{V} \mathrm{O}_{2 \max }$, baseline $\dot{V} \mathrm{O}_{2}$ values and time to achieve 90 or $95 \%$ of $\dot{V} \mathrm{O}_{2 \max }$

Time to exhaustion $\left(t_{\lim }\right)$ corresponded to the delay between the start and the end of the exercise. Time spent above $90 \%\left(t 90 \dot{V} \mathrm{O}_{2 \max }\right)$ or above $95 \%$ of $\dot{V} \mathrm{O}_{2 \max }\left(t 95 \dot{V} \mathrm{O}_{2 \max }\right)$ was determined from the $\dot{V} \mathrm{O}_{2}$ values higher or equal to 90 or $95 \%$ of $\dot{V} \mathrm{O}_{2 \max }$ of the day. The $\dot{V} \mathrm{O}_{2}$ values before the exercise were averaged over a 2 min period during $\mathrm{IE}_{\mathrm{P}}$ and $\mathrm{IE}_{\mathrm{A}}$ to determine the baseline $\dot{V} \mathrm{O}_{2}$ values $\left(\dot{V} \mathrm{O}_{2 \text { base }}\right)$. Time to achieve $90 \%\left(\mathrm{tt} 90 \dot{V} \mathrm{O}_{2 \max }\right)$ or $95 \%$ of $\dot{V} \mathrm{O}_{2 \max }(t t 95$ $\left.\dot{V} \mathrm{O}_{2 \max }\right)$ was the time to achieve 90 or $95 \%$ of $\dot{V} \mathrm{O}_{2 \max }$ of the day.

\section{Determination of $\dot{V} \mathrm{O}_{2}$ at $50 \%$ of MAV}

For each subject the $\dot{V} \mathrm{O}_{2}$ at each stage of the graded test was averaged over the last seconds of exercise (30 s). Then, individual $\dot{V} \mathrm{O}_{2}$ vs. velocity relationship were calculated. The $\dot{V} \mathrm{O}_{2}$ values at the last stage were not included in the calculation. The $\dot{V} \mathrm{O}_{2}$ at $50 \%$ of MAV were interloped from this relationship.

Determination of the time course of $\dot{V}_{\mathrm{E}}, V_{\mathrm{T}}, \mathrm{fr}$, $\dot{V} \mathrm{CO}_{2}$, and estimated $\mathrm{PaCO}_{2}$

$\dot{V}_{\mathrm{E}}, V_{\mathrm{T}}, \mathrm{fr}$, and $\dot{V} \mathrm{CO}_{2}$ values were averaged over a $15 \mathrm{~s}$ period during $\mathrm{IE}_{\mathrm{P}}$ and $\mathrm{IE}_{\mathrm{A}}$. Then, the values were averaged over 10 periods, each corresponding to $10 \%$ of the durations of individual $t_{\mathrm{lim}}$. The method used to determine the time course of estimated $\mathrm{PaCO}_{2}$ was the same one as that presented above. The time course of $\dot{V}_{\mathrm{E}}, V_{\mathrm{T}}, \mathrm{fr}, \dot{V} \mathrm{CO}_{2}$, and $\mathrm{PaCO}_{2}$ are presented in Figs. 3 and 4 for a representative subject.

Blood sample collection

Finger tip blood samples $(70 \mu \mathrm{l})$ were taken at rest and 3 min after exercise for measurement of $\mathrm{pH}$ and ion bicarbonate concentration $\left(\left[\mathrm{HCO}_{3}^{-}\right]\right)$with an electrolyte portable analyzer $\left(\mathrm{ABL}^{\mathrm{TM}} 77\right.$, SenDx Medical, Inc., USA).

\section{Statistical analysis}

The results are expressed as means $( \pm \mathrm{SD})$. Difference in $\dot{V} \mathrm{O}_{2 \max }$ determined during the maximal graded test and $\dot{V} \mathrm{O}_{2 \max }$ of the day were compared with a one-way repeated-measures analysis of variance (ANOVA). Mean experimental values were compared using paired $t$ tests.

Mean metabolic values were compared using twoway ANOVA with repeated measures for the "time" parameter. Honest significant difference (HSD) Tukey and Student-Newman-Keuls post hoc tests were used in the case of significant main effect and interactions, respectively. The size of the effect of recovery intensity was calculated from the Omega square coefficient $\left(\omega^{2}\right)$ usually used to asses the amount of variance attributed to each significant effect (Abdi 1987) following the equation: 


$$
\begin{aligned}
\omega^{2}= & {\left[\left(\mathrm{SS}_{\text {Between-subjects }}-(k-1) \times\left(\mathrm{MS}_{\mathrm{Within}-\text { subjects }}\right) /\right.\right.} \\
& \left.\left(\mathrm{SS}_{\text {Total }}+\mathrm{MS}_{\mathrm{Within}-\text { subjects }}\right)\right] \times 100,
\end{aligned}
$$

where SS is the sum of squares, MS is the mean square, and $k$ is the number of testing times.

For all statistical analyses, a $P$ value of 0.05 (alpha) was accepted as the level of significance. If a difference was not statistically significant at the chosen alpha level, the beta risk of an erroneous conclusion of equivalence was chosen as a $P$ value less than or equal to 0.2 .

\section{Results}

Maximal graded test and MAV +1 tests

The mean values for MAV, $\dot{V} \mathrm{O}_{2 \max }, \mathrm{HR}_{\max }$, and $R_{\max }$ were $17.9 \pm 0.4 \mathrm{~km} \mathrm{~h}^{-1}, 57.4 \pm 6.1 \mathrm{ml} \mathrm{min}^{-1} \mathrm{~kg}^{-1}$, $201.2 \pm 8.2 \mathrm{bpm}$ and $1.12 \pm 0.05$, respectively. The $\dot{V} \mathrm{O}_{2 \max }$ of the day measured during MAV +1 tests are presented in Table 1. Mean $\dot{V} \mathrm{O}_{2 \max }$ determined during maximal graded test and $\dot{V} \mathrm{O}_{2 \max }$ of the day values obtained during $\mathrm{IE}_{\mathrm{A}}$ and $\mathrm{IE}_{\mathrm{P}}$ were not significantly different. For each subject a significant relationship was found between $\dot{V} \mathrm{O}_{2}$ and velocity $\left(r^{2}=0.92 \pm 0.06\right)$. Mean $\dot{V} \mathrm{O}_{2} \quad\left(34.4 \pm 4.02 \mathrm{ml} \mathrm{min} \mathrm{kg}^{-1}\right)$ at $50 \%$ of MAV were significantly $(P<0.05)$ higher than mean $\dot{V} \mathrm{O}_{2}\left(28.71 \pm 3.07 \mathrm{ml} \mathrm{min}^{-1} \mathrm{~kg}^{-1}\right)$ at $50 \%$ of $\dot{V} \mathrm{O}_{2 \max }$. Mean $\dot{V} \mathrm{O}_{2}$ at $50 \%$ of MAV corresponded to $60.2 \pm 7.4 \%$ of $\dot{V} \mathrm{O}_{2 \max }$

\section{Intermittent exercises}

Mean values for parameters measured during IE are presented in Table 1. $t_{\text {lim }}$ was significantly longer $(P<0.01)$ for $\mathrm{IE}_{\mathrm{P}}$ than $\mathrm{IE}_{\mathrm{A}}$. In absolute value, there were no significant difference between $t 90 \dot{V} \mathrm{O}_{2 \max }$ and $t 95 \dot{V} \mathrm{O}_{2 \max }$ calculated for $\mathrm{IE}_{\mathrm{P}}$ and $\mathrm{IE}_{\mathrm{A}}(P>0.2)$.
However, in relative value $\left(\% t_{\text {lim }}\right) t 90 \dot{V} \mathrm{O}_{2 \max }$ and $t 95 \dot{V} \mathrm{O}_{2 \max }$ represented a significantly $(P<0.001$ and $P<0.05$, respectively) higher percentage of $t_{\text {lim }}$ for $\mathrm{IE}_{\mathrm{A}}$ than for $\mathrm{IE}_{\mathrm{P}}$. During $\mathrm{IE}_{\mathrm{P}}$ one subject failed to reach $95 \%$ of $\dot{V} \mathrm{O}_{2 \max }$ of the day, while all subjects reached $95 \%$ of $\dot{V} \mathrm{O}_{2 \max }$ of the day for $\mathrm{IE}_{\mathrm{A}}$. For $\mathrm{IE}_{\mathrm{P}}$ as for $\mathrm{IE}_{\mathrm{A}}$ all subjects reached $90 \%$ of $\dot{V} \mathrm{O}_{2 \max }$ of the day. Mean $t t 90 \dot{V} \mathrm{O}_{2 \max }$ and $t t 95 \dot{V} \mathrm{O}_{2 \max }$ were not significantly different between $\mathrm{IE}_{\mathrm{P}}$ and $\mathrm{IE}_{\mathrm{A}}$.

The $\mathrm{pH}$ and $\left[\mathrm{HCO}_{3}^{-}\right]$mean values revealed significant main recovery intensity effects $\left(F_{1,14}=4.66, P<\right.$ $0.05, F_{1,14}=5.91, P<0.05$, respectively), explaining $74 \%\left(\omega^{2}\right)$ and $23 \%$ of the total variance, respectively. The post hoc analysis revealed significant differences $(P<0.05-0.001)$ between the two conditions of recovery intensity (Fig. 2a, b).

The evolution of $\dot{V} \mathrm{O}_{2}$, fr, $V_{\mathrm{T}}$, and $\dot{V}_{\mathrm{E}}$ time course and $\dot{V} \mathrm{O}_{2}, \dot{V} \mathrm{CO}_{2}$ and estimated $\mathrm{PaCO}_{2}$ time course during $\mathrm{IE}_{\mathrm{P}}$ for one representative subject are presented in Figs. 3 and 4, respectively.

\section{Discussion}

The purpose of this study was to compare, during a 30 sIE, the effects of the recovery mode (active/passive) on $t 90 \dot{V} \mathrm{O}_{2 \max }$ and $t 95 \dot{V} \mathrm{O}_{2 \max }$. Short intermittent exercise such as the 30sIE realized at $105 \%$ of MAV is of particular interest as it enables subjects to reach and maintain a high percentage of $\dot{V} \mathrm{O}_{2 \max }$ (Millet et al. 2003a). In this study the choice of exercise intensity was based on previous studies. Indeed, supra-maximal ( $>100 \%$ of MAV) 30sIE have been shown to allow the improvement of endurance performance (Septo et al. 1999; Tabata et al. 1996) thanks to an increase in $\dot{V} \mathrm{O}_{2 \max }$ which seems to be due, in particular, to the increase in oxidative enzyme activities (citrate synthase, succinate dehydrogenase) (Holloszy et al. 1984). Many authors have hypothesized that the $\dot{V} \mathrm{O}_{2 \max }$ improvement with training is correlated with time

\begin{tabular}{|c|c|c|c|c|c|c|c|c|c|}
\hline Test & $\begin{array}{l}V \mathrm{O}_{2 \max } \text { of the day } \\
\left(\mathrm{ml} \mathrm{min}^{-1} \mathrm{~kg}^{-1}\right)\end{array}$ & $\begin{array}{l}t_{\lim } \\
(\mathrm{s})\end{array}$ & $\begin{array}{l}t 90 V \mathrm{O}_{2 \max } \\
(\mathrm{s})\end{array}$ & $\begin{array}{l}t 90 V \mathrm{O}_{2 \max } \\
\left(\% t_{\mathrm{lim}}\right)\end{array}$ & $\begin{array}{l}t 95 V \mathrm{O}_{2 \max } \\
(\mathrm{s})\end{array}$ & $\begin{array}{l}t 95 V \mathrm{O}_{2 \max } \\
\left(\% t_{\mathrm{lim}}\right)\end{array}$ & $\begin{array}{l}V \mathrm{O}_{2 \text { base }} \\
\left(\mathrm{ml} \mathrm{min}^{-1} \mathrm{~kg}^{-1}\right)\end{array}$ & $\begin{array}{l}t t 90 V \mathrm{O}_{2 \max } \\
(\mathrm{s})\end{array}$ & $\begin{array}{l}t t 95 V \mathrm{O}_{2 \max } \\
(\mathrm{s})\end{array}$ \\
\hline $\mathrm{IE}_{\mathrm{A}}$ & $57.8^{\mathrm{NS}}(8.4)$ & $1072^{* *}(388)$ & $746^{\mathrm{NS}}(417)$ & $67.7^{* * * *}(19)$ & $459^{\mathrm{NS}}(332)$ & $42.1^{*}(27)$ & $10.94^{\mathrm{NS}}(2.6)$ & $82^{\mathrm{NS}}(43)$ & $121^{\mathrm{NS}}(77)$ \\
\hline $\mathrm{IE}_{\mathrm{P}}$ & $55.0(7.2)$ & $2145(829)$ & 548 (499) & 24.2 (19) & $316(360)$ & $13.8(15)$ & $12.91(3.2)$ & $113(100)$ & $164(218)$ \\
\hline
\end{tabular}

Table 1 Mean $( \pm \mathrm{SD})$ data measured for the two intermittent exercises with passive $\left(\mathrm{IE}_{\mathrm{P}}\right)$ and active $\left(50 \%\right.$ of $\left.\mathrm{MAV}-\mathrm{IE}_{\mathrm{A}}\right)$ recovery

$V \mathrm{O}_{2 \max }$ of the day: $V \mathrm{O}_{2 \max }$ determined during the MAV +1 test; $t_{\text {lim }}$ : total exercise duration; $t 90 V \mathrm{O}_{2 \text { max }}$ : time spent above $90 \%$ of $V \mathrm{O}_{2 \max }$ of the day expressed in absolute (s) and in relative $\left(\% t_{\mathrm{lim}}\right)$ values; $t 95 V \mathrm{O}_{2 \max }$ : time spent above $95 \%$ of $V \mathrm{O}_{2 \mathrm{max}}$ of the day expressed in absolute (s) and in relative ( $\left.\% t_{\text {lim }}\right)$ values; $V \mathrm{O}_{2 \text { base }}$ : mean values of $V \mathrm{O}_{2}$ over 2 min before the exercise; $t t 90 V \mathrm{O}_{2 m a x}$ : time to achieve $90 \%$ of $V \mathrm{O}_{2 \max } ; t t 95 V \mathrm{O}_{2 \max }$ : time to achieve $95 \%$ of $V \mathrm{O}_{2 \max }$

NS: no significant difference

Significant difference between $\mathrm{IE}_{\mathrm{A}}$ and $\mathrm{IE}_{P} ; * P<0.05 ; * * P<0.01 ; * * * P<0.001$ 
Fig. 2 Mean $( \pm \mathrm{SD}) \mathrm{pH}$

(a) and bicarbonate ion concentration $\left(\left[\mathrm{HCO}_{3}^{-}\right]\right.$

(b) measured at rest and $3 \mathrm{~min}$ after intermittent exercise with passive $\left(\mathrm{IE}_{\mathrm{P}}\right)$ and active $\left(50 \%\right.$ of MAV $\left.-\mathrm{IE}_{\mathrm{A}}\right)$ recovery. $\bullet$ indicates $\mathrm{IE}_{\mathrm{A}}$. $\triangle$ indicates $\mathrm{IE}_{\mathrm{P}}$. Significant difference: $* * * P<0.001$;

\# $P<0.05$; \#\# $P<0.01$

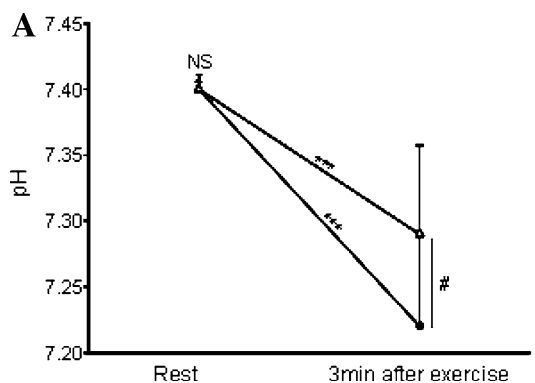

spent at a high level of oxygen uptake (close to $\dot{V} \mathrm{O}_{2 \max }$ ) during each exercise session (Hermansen 1981; Hill and Rowell 1997; Billat et al. 2000). Thus, for

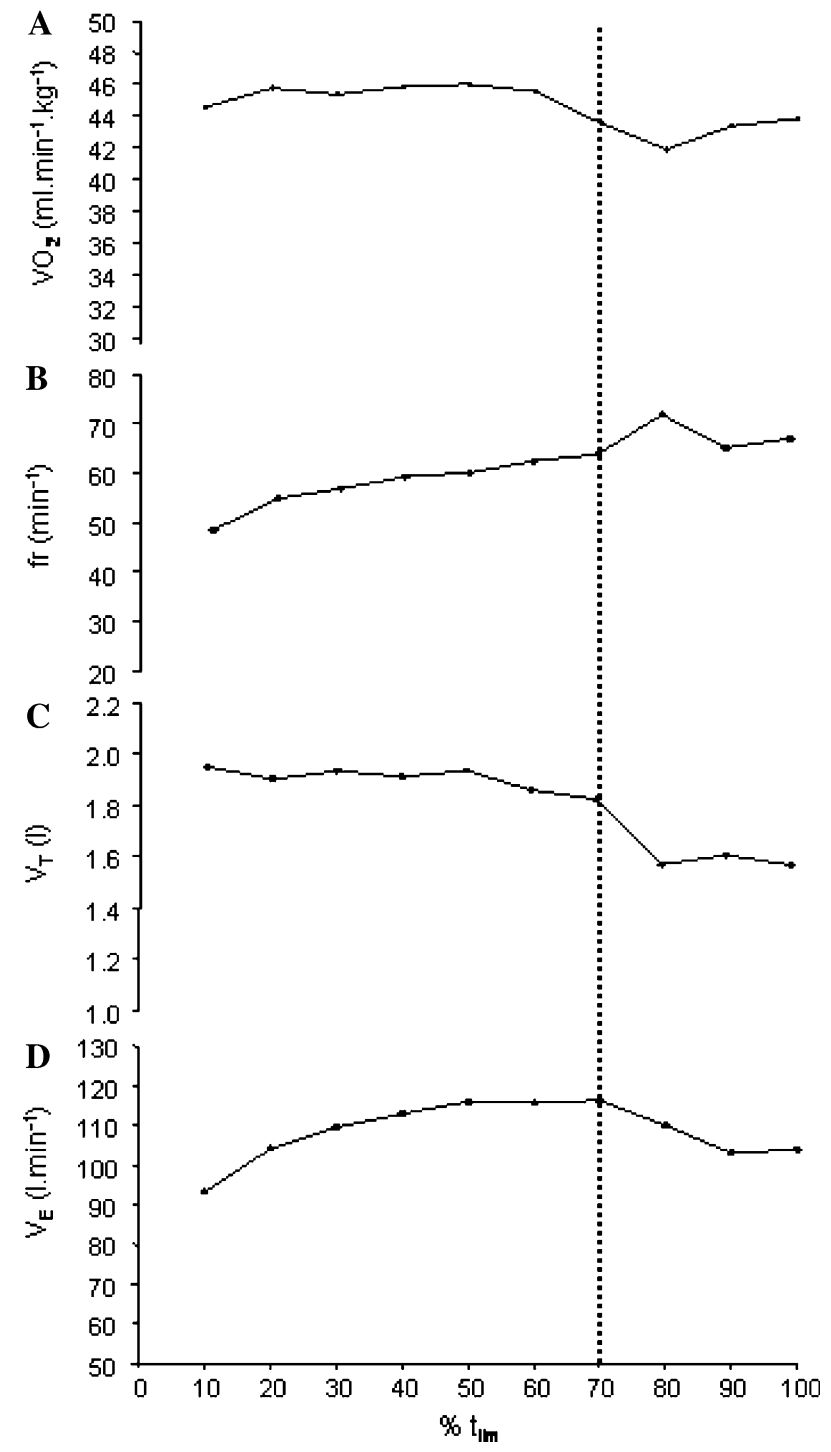

Fig. 3 Time course of oxygen consumption $\left(\dot{V} \mathrm{O}_{2}, \mathrm{~A}\right)$, respiratory frequency $(\mathrm{fr}, \mathrm{B})$, tidal volume $\left(V_{\mathrm{T}}, \mathrm{C}\right)$ and ventilation $\left(\dot{V}_{\mathrm{E}}, \mathrm{D}\right)$ during intermittent exercises with passive recovery for one representative subject

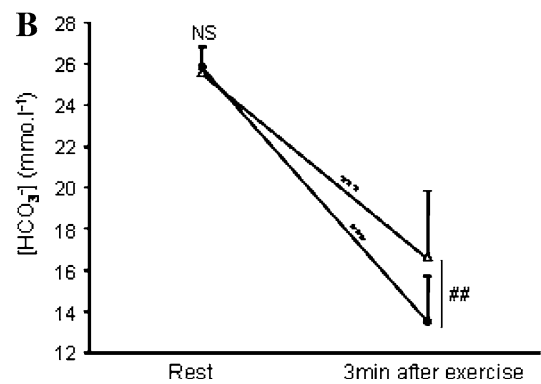

some years, $t 95 \dot{V} \mathrm{O}_{2 \max }$ (or $t 90 \dot{V} \mathrm{O}_{2 \max }$ ) value has generally been measured (Millet et al. 2003a; Dupont and Berthoin 2004; Tardieu-Berger et al. 2004). Millet et al. (Millet et al. 2003b) have shown that during 30 sIE (active recovery), $t 95 \dot{V} \mathrm{O}_{2 \max }$ was longer when subjects ran at $105 \%$ of velocity associated with $\dot{V} \mathrm{O}_{2 \max }\left(\mathrm{v} \dot{V} \mathrm{O}_{2 \max }\right)$ compared with 30 sIE at $100 \%$ of $\mathrm{v} \dot{V} \mathrm{O}_{2 \max }$. These results support the choice of exercise intensity $(105 \%$ of MAV) in the present study. The active recovery intensity at $50 \%$ of MAV has been adopted because it is certainly one of the most chosen

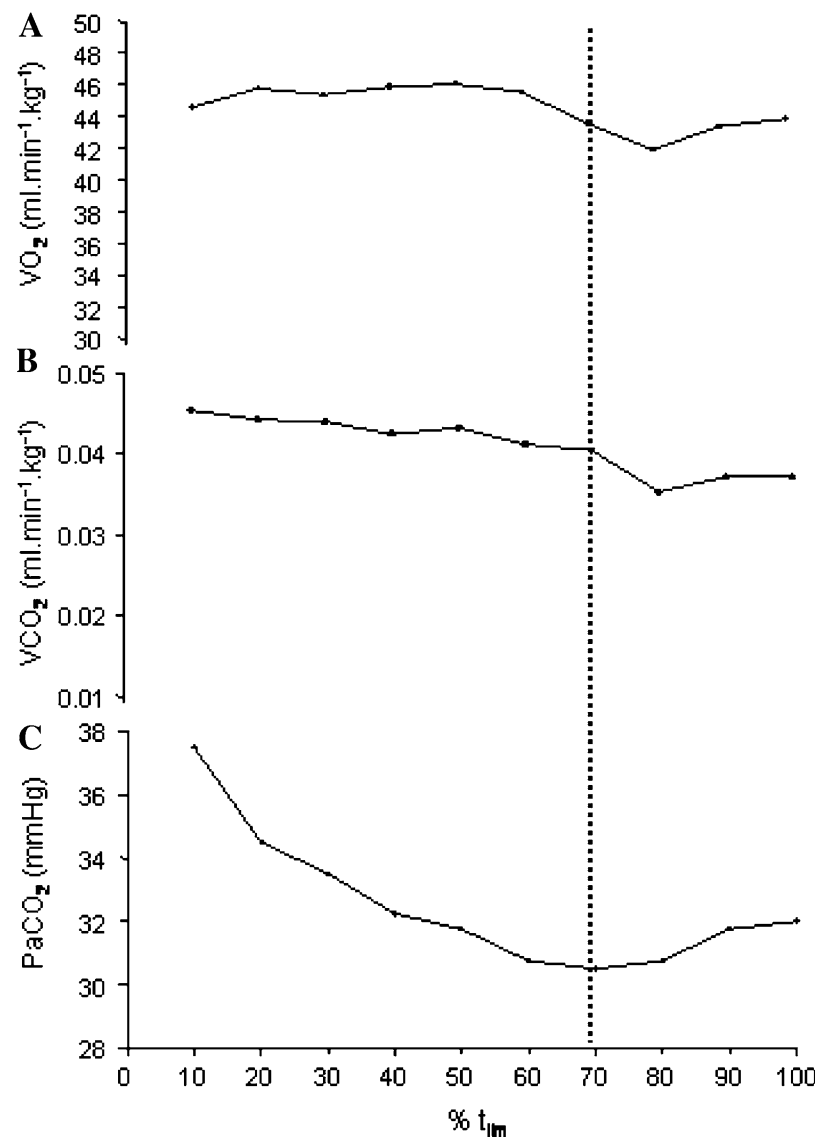

Fig. 4 Time course of oxygen consumption $\left(\dot{V} \mathrm{O}_{2}, \mathrm{~A}\right)$, carbon dioxide output $\left(\dot{V} \mathrm{O}_{2}, \mathrm{~B}\right)$ and estimated arterial pressure of $\mathrm{CO}_{2}$ $\left(\mathrm{PaCO}_{2}, \mathrm{C}\right)$ during intermittent exercises with passive recovery for one representative subject 
in the scientific literature (Billat et al. 2000; Millet et al.2003a, b; Tardieu-Berger et al. 2004) and because it is a current intensity used by the athletes during their training sessions. This intensity is generally chosen as it allows a higher lactate removal, even if the link between lactate removal and a better recovery could be discussed (Gisolfi et al. 1966; Baldari et al. 2005). Two previous studies realized on the treadmill showed that the best lactate elimination occurs for recovery intensities of $52 \%$ (Gisolfi et al. 1966) and $63 \%$ of $\dot{V} \mathrm{O}_{2 \max }$ (Hermansen and Stensvold 1972). In the present study, recovery intensity at $50 \%$ of the MAV corresponds to an average value of $60.2 \%$ of $\dot{V} \mathrm{O}_{2 \max }$.

In the present study, it was hypothesized that during a 30sIE, active recovery would allow an increase in $t 90 \dot{V} \mathrm{O}_{2 \max }$ and $t 95 \dot{V} \mathrm{O}_{2 \max }$ due to a decrease in time to achieve 90 or $95 \%$ of $\dot{V} \mathrm{O}_{2 \max }$ with active recovery compared with passive recovery. Our findings are likely to suggest that $t_{\text {lim }}$ was significantly longer during $\mathrm{IE}_{\mathrm{P}}$ than $\mathrm{IE}_{\mathrm{A}}$. However, $t 90 \dot{V} \mathrm{O}_{2 \max }$ and $t 95 \dot{V} \mathrm{O}_{2 \max }$ were not significantly different $(P>0.2)$ according to the recovery mode (Table 1 ). Similarly, $t t 90 \quad \dot{V} \mathrm{O}_{2 \max }$ and $t t 95 \dot{V} \mathrm{O}_{2 \max }$ were not significantly different between $\operatorname{IE}_{\mathrm{P}}$ and $\mathrm{IE}_{\mathrm{A}}(P>0.2)$. In this line, our hypothesis seems to be not verified. Our results differ from the scientific literature which brings back faster $\dot{V} \mathrm{O}_{2}$ kinetics during an intermittent exercise with an active recovery compared with a passive recovery (Dorado et al. 2004). In the present study, the $\dot{V} \mathrm{O}_{2 \text { base }}$ values before $\mathrm{IE}_{\mathrm{P}}$ and $\mathrm{IE}_{\mathrm{A}}$ could not explain similar $t t 90 \dot{V} \mathrm{O}_{2 \max }$ or $t t 95 \dot{V} \mathrm{O}_{2 \max }$ values. The lack of difference in $t t 90 \dot{V} \mathrm{O}_{2 \max }$ or $t t 95 \dot{V} \mathrm{O}_{2 \max }$ between $\mathrm{IE}_{\mathrm{P}}$ and $\mathrm{IE}_{\mathrm{A}}$ could be explained by the fact that recovery intensity chosen for $\mathrm{IE}_{\mathrm{A}}$ was not high enough. Indeed, Gerbino et al. (1996) or MacDonald et al. (1997) found that prior moderate exercise had no effect on the subsequent $\dot{V} \mathrm{O}_{2}$ kinetic during heavy exercise while prior heavy exercise significantly speeded the $\dot{V} \mathrm{O}_{2}$ kinetics during subsequent heavy exercise. Another hypothesis is that beneficial effects or otherwise of prior exercise are likely to depend on many factors, including prior exercise and recovery durations (Jones et al. 2003). The 30sIE model of the present study is an alternation of short ( $30 \mathrm{~s})$ exercise and recovery periods. The influence on $\dot{V} \mathrm{O}_{2}$ kinetics during the subsequent heavy exercise was observed when long prior exercise ( $>$ than $2 \mathrm{~min}$ ) was followed by 2,6 or $12 \mathrm{~min}$ of recovery (Dorado et al. 2004; Gerbino et al. 1996). We can hypothesise that, if the recovery is short (30 s) the $\dot{V} \mathrm{O}_{2}$ prior to the start of each high intensity bout is already high, even during passive recovery and, hence, it is less likely to observe a significant acceleration of the time course of $\dot{V} \mathrm{O}_{2}$, but because the time course is already as fast as it can be. Other studies should, however, be carried out to confirm this hypothesis.

Effects of recovery mode on total exercise duration $\left(t_{\lim }\right)$

Our results highlight the fact that for a 30sIE at 105\% of MAV longer $t_{\text {lim }}$ was observed with passive recovery than with active recovery (50\% of MAV). Association of the $\mathrm{pH}$ decrease and the appearance of fatigue during short intensive exercise have been observed in animals (Metzger and Fitts 1987) and in humans (Hermansen 1981; Sahlin 1983). This relation has been shown in previous studies which have demonstrated that metabolic acidosis, (induced by ammonium chloride ingestion) was associated with a reduction in performance during an intensive exercise on an ergocycle (Jones et al. 1977; Sutton et al. 1981). Recently, Stackhouse et al. (2001) suggested that the muscular contraction process seems to be limited by acidosis which can be considered as the main cause of muscular fatigue during supra-maximal exercise. Taking into account the close relationship which binds the $\mathrm{H}^{+}$ions to $\left[\mathrm{HCO}_{3}^{-}\right]$, the concentration decrease in blood $\left[\mathrm{HCO}_{3}^{-}\right]$seems to account for the acidosis level induced by exercise (Nielsen et al. 2002). Then, the longer $t_{\text {lim }}$ observed during $\mathrm{IE}_{\mathrm{P}}$ could be explained by the higher $\mathrm{pH}$ and $\left[\mathrm{HCO}_{3}^{-}\right]$values observed at the end of this exercise (Fig. 2a, b). However, fatigue was reached at different $\mathrm{pH}$, meaning that capillary blood $\mathrm{pH}$ was not the main factor determining fatigue. In addition, some of these changes may have been elicited by the recovery exercise itself. To rule out the latter we need to know the $\mathrm{pH},\left[\mathrm{HCO}_{3}^{-}\right]$response to the recovery exercise when performed alone under steady state conditions.

Effects of recovery mode on time spent at high percentage of $\dot{V} \mathrm{O}_{2 \max }$

The two intermittent exercise models led all subjects to reach at least $90 \%$ of $\dot{V} \mathrm{O}_{2 \max }$ of the day, but during $\mathrm{IE}_{\mathrm{P}}$ one subject failed to reach $95 \%$ of $\dot{V} \mathrm{O}_{2 \max }$. These results indicate that, for both IE, the interaction between intensity and duration of exercise and recovery periods was adequate to allow subjects to reach and to maintain a high percentage of $\dot{V} \mathrm{O}_{2 \max }$. When the recovery periods are sufficiently long (at least $30 \mathrm{~s}$ ), active recovery is generally recommended to increase performance (Signorile et al. 1993; Bogdanis et al. 1996). As indicated by the $P$ values $(P>0.2)$, our findings might suggest that recovery mode has no influence on $t 95 \dot{V} \mathrm{O}_{2 \max }\left(\right.$ or $\left.t 90 \dot{V} \mathrm{O}_{2 \max }\right)$ in absolute 
values. Our results show that during the $30 \mathrm{sIE}$, both recovery mode allow similar amounts of time spent at or near $\dot{V} \mathrm{O}_{2 \max }$ and should therefore impose similar levels of stimuli on the oxygen transport and utilization systems. It should be mentioned however that when $t 95 \dot{V} \mathrm{O}_{2 \max }\left(\right.$ or $t 90 \dot{V} \mathrm{O}_{2 \max }$ ) were expressed in relative values $\left(\% t_{\text {lim }}\right)$, a significantly higher percentage of $t_{\text {lim }}$ for $\mathrm{IE}_{\mathrm{A}}$ than for $\mathrm{IE}_{\mathrm{P}}$ can be observed. Then, the $30 \mathrm{sIE}$ active recovery seems to be more efficient than passive recovery when the sole objective of the exercise is to sustain a high percentage of $\dot{V} \mathrm{O}_{2 \max }$ since one spends proportionally less time running for the same value of $t 95 \dot{V} \mathrm{O}_{2 \max } \quad\left(\right.$ or $\left.t 90 \dot{V} \mathrm{O}_{2 \max }\right)$. Nevertheless, Noakes (1991) has shown that cardio-ventilatory solicitation is not the only way to develop endurance performance. In fact, $t_{\text {lim }}$ at high intensity has an effect on muscular adaptations. Our results show that passive recovery allows a longer time at high intensity and should therefore impose a greater stimulus on the neuromuscular system. In this way, it seems that passive recovery during a 30sIE is also of interest to develop endurance performance. However, it seems necessary to confirm these results during a longitudinal study.

The present results were in line with an earlier study (Dupont and Berthoin 2004), which showed that during a $15 \mathrm{sIE}(15 \mathrm{~s}$ at $120 \%$ of MAV alternated with $15 \mathrm{~s}$ active or passive recovery), passive recovery induced longer $t_{\lim }$ with a similar $t 90 \dot{V} \mathrm{O}_{2 \max }$ or $t 95 \dot{V} \mathrm{O}_{2 \max }$. A lower level of $\dot{V} \mathrm{O}_{2}$ throughout the end of $\mathrm{IE}_{\mathrm{P}}$ (Fig. $4 \mathrm{~A}$ ) can explain the similar $t 90 \dot{V} \mathrm{O}_{2 \max }$ and $t 95 \dot{V} \mathrm{O}_{2 \max }$ during $\mathrm{IE}_{\mathrm{P}}$ associated with a longer $t_{\text {lim. }}$. This decreased $\dot{V} \mathrm{O}_{2}$ before exhaustion could be explained by a $\dot{V}_{\mathrm{E}}$ decrease (Fig. 3D). The decrease in $\dot{V}_{\mathrm{E}}$ begins at around $70 \%$ of $t_{\text {lim }}$ (Fig. 3D) and could be explained by a decreased $V_{\mathrm{T}}$ (Fig. 3C). Indeed, after $70 \%$ of $t_{\text {lim }}$, the increase in fr (Fig. 3B) seems to be insufficient to prevent the decreased $V_{\mathrm{T}}$. The increased $\mathrm{fr}$, associated with $V_{\mathrm{T}}$ reduction, can be an indirect sign of respiratory muscle fatigue (Gallagher et al. 1985) and can partly explain the decreased $\dot{V} \mathrm{O}_{2}$.

According to the following equation:

$$
\dot{V}_{\mathrm{E}}=863 \times \dot{V} \mathrm{CO}_{2} /\left[\mathrm{Paco}_{2} \times\left(1-V_{\mathrm{D}} / V_{\mathrm{T}}\right)\right]
$$

$\left(V_{\mathrm{D}}\right.$ : dead space volume; Whipp etal. 1984)

$\dot{V}_{\mathrm{E}}$ and $\dot{V} \mathrm{CO}_{2}$ are coupled one with the other via $\mathrm{PaCO}_{2}$. Indeed, a reduction in $\mathrm{PaCO}_{2}$ requires a greater ventilatory response per unit of $\mathrm{CO}_{2}$, while an increase in $\mathrm{PaCO}_{2}$ requires less ventilation (Whipp et al. 1984). Hence, in this study our results about hypoventilation before exhaustion were in agreement with the scientific literature. Indeed the decreased
$\dot{V}_{\mathrm{E}}$ was associated with an increase in estimated $\mathrm{PaCO}_{2}$ and a decrease in $\dot{V} \mathrm{CO}_{2}$ (Fig. 4).

The decreased $\dot{V} \mathrm{O}_{2}$ before exhaustion has already been observed during continuous $t_{\text {lim }}$ realized at $95 \%$ of MAV by Perrey et al. (2002). According to these authors, several physiological mechanisms could explain this decreased $\dot{V} \mathrm{O}_{2}$ notably respiratory muscle fatigue (Gallagher et al. 1985) and alteration of arterio-venous $\mathrm{O}_{2}$ difference. The latter could be due to a vasoconstriction in active lower limb muscles, a decrease in arterial hemoglobin saturation or an inhibition of oxidative phosphorylation (Perrey et al. 2002). However, this possibility has recently been questioned by Gonzales-Alonso and Calbet (2003). These authors showed that leg arterio-venous $\mathrm{O}_{2}$ difference and $\mathrm{O}_{2}$ extraction increased progressively until the end of exercise and preclude any sudden drop in $\mathrm{O}_{2}$ diffusion at the time $\mathrm{O}_{2}$ delivery to the leg was falling. Thus, the greater decline in convective $\mathrm{O}_{2}$ transport to the leg muscles is likely to result from a reduction in leg $\dot{V} \mathrm{O}_{2}$ before exhaustion (Gonzalez-Alonso and Calbet 2003). Hence, the reduction in $\dot{V} \mathrm{O}_{2}$ before exhaustion has been hypothesized by Gonzales-Alonso and Calbet (2003) to be due to a decrease in cardiac output $(Q)$ and leg blood flow. The high demand for respiratory muscle blood flow compromises lower limb muscle flow because of sympathetically mediated vasoconstriction (Harms et al. 1997). Moreover, GonzalesAlonso and Calbet (2003) showed that the impaired systemic and skeletal muscle aerobic capacity that precedes fatigue was largely related to the failure of the heart to maintain cardiac output and oxygen delivery to locomotive muscles. Other studies should however be, carried out to confirm this hypothesis.

\section{Conclusion}

In conclusion, although the scientific literature and empirical knowledge advocate active recovery, passive recovery also seems to be adapted to solicit the aerobic system at a high level. Our results are likely to suggest that active recovery allows a shorter $t_{\mathrm{lim}}$ with proportionally longer $t 90 \dot{V} \mathrm{O}_{2 \max }$ and $t 95 \dot{V} \mathrm{O}_{2 \max }$, whereas passive recovery allows a longer running time for similar $t 90 \dot{V} \mathrm{O}_{2 \max }$ and $t 95 \dot{V} \mathrm{O}_{2 \max }$. It seems that the two recovery modes are efficient to solicit the aerobic system during an intermittent exercise. These results suggest that the choice of recovery mode depends on exercise objectives. In other words, if the sole objective of a training session is to improve $\dot{V} \mathrm{O}_{2 \max }$, active recovery (at $50 \%$ of MAV) should be chosen. A passive recovery should be chosen to both improve 
$\dot{V} \mathrm{O}_{2 \max }$ and induce muscular adaptations. Longitudinal studies should be carried out to confirm the interest of passive recovery during short intermittent training to increase aerobic fitness. Moreover, currently, most studies suggest that the percentage of $\dot{V} \mathrm{O}_{2 \max }$ attained and the time for which it is sustained above $90 \%$ $\dot{V} \mathrm{O}_{2 \max }$ could serve as good criteria to judge the effectiveness of the stimulus to improve aerobic fitness. It would however be interesting to confirm the relevance of this parameter in the increase of $\dot{V} \mathrm{O}_{2 \max }$ with training studies.

Acknowledgments The authors would like to thank the "Plateau Technique de Médecine du Sport" of Laval (France) for there technical assistance. We would also like to acknowledge the financial support of the "Direction Departmental de la Jeunesse et des Sports" of Loire Atlantique (France).

\section{References}

Åstrand I, Åstrand PO, Christensen EH, Hedman R (1960) Intermittent muscular work. Acta Physiol Scand 48:448-453

Abdi H (1987) Introduction au traitement statistique des données expérimentales. Grenoble. Presse Universitaire de Grenoble

Baldari C, Videira M, Madeira F, Sergio J, Guidetti L (2005) Blood lactate removal during recovery at various intensities below the individual anaerobic threshold in triathletes. J Sports Med Phys Fitness 45(4):460-466

Bangsbo J, Gollnick PD, Johansen L, Saltin B (1994) Muscle lactate metabolism in recovery from intense exhaustive exercise: Impact of light exercise. J Appl Physiol 77:1890 1895

Billat V, Bernard O, Pinoteau J, Petit B, Koralsztein JP (1994) Time to exhaustion at $V \mathrm{O}_{2 \max }$ and lactate steady state velocity in sub-elite long-distance runners. Arch Int Physiol Biochem Biophys 102:215-219

Billat VL, Slawinski J, Bocquet V, Demarle A, Lafitte L, Chassaing P, Koralsztein JP (2000) Intermittent runs at the velocity associated with maximal oxygen uptake enables subjects to remain at maximal oxygen uptake for a longer time than intense but submaximal runs. Eur J Appl Physiol 81:188-196

Bogdanis GC, Nevill ME, Lakomy HK, Graham CM, Louis G (1996) Effects of active recovery on power output during repeated maximal sprint cycling. Eur J Appl Physiol 74:461469

Dorado C, Sanchis-Moysi J, Calbert JAL (2004) Effects of recovery mode on performance, $\mathrm{O}_{2}$ uptake, and $\mathrm{O}_{2}$ deficit during high intensity intermittent exercise. Can J Appl Physiol 29(3):227-244

Dupont G, Berthoin S (2004) Time spent at a high percentage of $V \mathrm{O}_{2 \max }$ for short intermittent runs: active versus passive recovery. Can J Appl Physiol 29(suppl):S3-S16

Dupont G, Blondel N, Berthoin S (2003a) Performance for short intermittent runs: active vs. passive recovery. Eur J Appl Physiol 89:548-554

Dupont G, Blondel N, Berthoin S (2003b) Time spent at $V \mathrm{O}_{2 \max }$ : a methodological issue. Int J Sports Med 24:291-297

Fox E (1975) Differences in metabolic alterations with sprint versus endurance interval training. In: Howald $\mathrm{H}$, Poortmans
J (eds) Metabolic adaptation to prolonged physical exercise. Birkha-user, Basel, pp 119-126

Gallagher CG, Hof VI, Younes M (1985) Effect of inspiratory muscle fatigue on breathing pattern. J Appl Physiol 59:1152-1158

Geor RJ, McCutcheon LJ, Hinchcliff KW (2000) Effects of warm-up intensity on kinetics of oxygen consumption and carbon dioxide production during high-intensity exercise in horses. Am J Vet Res 61:638-645

Gerbino A, Ward SA, Whipp BL (1996) Effects of prior exercise on pulmonary gas-exchange kinetics during high-intensity exercise in humans. J Appl Physiol 80:99-107

Gisolfi C, Robinson S, Turrel ES (1966) Effects of aerobic work performed during recovery from exhausting work. J Appl Physiol 21:1767-1772

Gonzalez-Alonso J, Calbet JAL (2003) Reductions in systemic muscle blood flow and oxygen delivery limit maximal aerobic capacity in humans. Circulation 107:824-830

Gorostiaga EM, Walter CB, Foster C, Hickson RC (1991) Uniqueness of interval and continuous training at the same maintained exercise intensity. Eur J Appl Physiol 63:101107

Harms CA, Badcock MA, McClaran SR, Pegelow DF, Nickele GA, Nelson WB, Dempsey JA (1997) Respiratory muscle work compromises leg blood flow during maximal exercise. J Appl Physiol 82:1573-1583

Hermansen L (1981) Effect of metabolic changes on force generation in skeletel muscle during maximal exercise. In: Ciba Foundation Symposium (C.F.S) (ed) Human muscle fatigue: physiological mechanisms, vol 82. Pitman Medical, London, pp 75-88

Hermansen L, Stensvold I (1972) Production and removal of lactate during exercise in man. Acta Physiol Scand 86:191201

Hill DW, Rowell AL (1997) Responses to exercise at the velocity associated with $V \mathrm{O}_{2 \max }$. Med Sci Sports Exerc 29:113-116

Hill DW, Williams CS, Burt SE (1997) Responses to exercise at $92 \%$ and $100 \%$ of the velocity associated with $V \mathrm{O}_{2 \max }$. Int J Sports Med 18:325-329

Holloszy JO, Coyle EF (1984) Adaptations of skeletal muscle to endurance exercise and their metabolic consequences. J Appl Physiol 56:831-838

Jones AM, Carter H (2000) The effect of endurance training on parameter of aerobic fitness. Sports Med 29(6):373-386

Jones NL, Sutton JR, Taylor R, Toews CJ (1977) Effect of pH on cardiorespiratory and metabolic responses to exercise. J Appl Physiol 43:959-964

Jones AM, Koppo K, Burnley M (2003) Effects of prior exercise on metabolic and gas exchange responses to exercise. Sports Med 33:949-971

Kuipers H, Verstappen FT, Keizer HA, Geurten P, van Kranenburg G (1985) Variability of aerobic performance in the laboratory and its physiologic correlates. Int J Sports Med 6:197-201

MacDonald MJ, Pedersen PK, Hughson RL (1997) Acceleration of $V \mathrm{O}_{2}$ kinetics in heavy submaximal exercise by hyperoxia and prior high-intensity exercise. J Appl Physiol 83:13181325

McLaughlin JE, King GA, Howley ET, Bassett DR Jr, Ainsworth BE (2001) Validation of the COSMED K4 b2 portable metabolic system. Int J Sports Med 22:280-284

Metzger JM and Fitts RH (1987) Role of intracellular pH in muscle fatigue. J Appl Physiol 62:1392-1397

Midgley AW, McNaughton LR (2006) Time at or near $V \mathrm{O}_{2 \max }$ during continuous and intermittent running: A review with special reference to considerations for the optimization of 
training protocols to elicit the longest time at or near $V \mathrm{O}_{2 \max }$. J Sports Med Phys fitness 46:1-14

Millet GP, Candau R, Fattori P, Bignet F, Varray A (2003a) $V \mathrm{O}_{2}$ responses to different intermittent runs at velocity associated with $V \mathrm{O}_{2 \max }$. Can J Appl Physiol 28:410-423

Millet GP, Libicz S, Borrani F, Fattori P, Bignet F, Candau R (2003b) Effects of increased intensity of intermittent training in runners with differing $V \mathrm{O}_{2}$ kinetics. Eur $\mathrm{J}$ Appl Physiol 90:50-57

Nielsen HB, Hein L, Svendsen LB, Secher NH, Quistorff B (2002) Bicarbonate attenuates intracellular acidosis. Acta Anaesthesiol Scand 46:579-584

Noakes TD (1991) Lore of running. Leisure Press, Champaign, IL, p 450

Perrey S, Candau R, Millet GY, Borrani F, Rouillon JD (2002) Decrease in oxygen uptake at the end of a high-intensity submaximal running in humans. Int J Sports Med 23:298304

Robinson DM, Robinson SM, Hume PA, Hopkins WG (1991) Training intensity of elite male distance runners. Med Sci Sports Exerc 23:1078-1082

Sahlin K (1983) Effect of acidosis on energy metabolism and force generation in skeletel muscle. In: Knuttgen $\mathrm{HG}$, Vogel JA, Portmans JR (eds) Biochemistry of exercise V. Human Kinetics, Champaign, pp 151-160

Septo NK, Hawley JA, Dennis SC, Hopkins WG (1999) Effects of different interval-training programs on cycling time-trial performance. Med Sci Sports Exerc 31:736-741

Signorile JF, Ingalls C, Tremblay LM (1993) The effects of active and passive recovery on short-term, high-intensity power output. Can J Appl Physiol 18:31-42
Spiro SG (1977) Exercise testing in clinical medicine. Br J Dis Chest 71:145-172

Stackhouse SK, Reisman DS, Binder-Macleod SA (2001) Challenging the role of $\mathrm{pH}$ in skeletal muscle fatigue. Phys Ter 81:1897-1903

Sutton JR, Jones NL, Toews CJ (1981) Effect of pH on muscle glycolysis during exercise. Clin Sci 61:331-338

Tabata I, Nishimura K, Kouzaki M, Hirai Y, Ogita F, Miyachi M, Yamamoto K (1996) Effects of moderate-intensity endurance and high-intensity intermittent training on anaerobic capacity and $V \mathrm{O}_{2 \max }$. Med Sci Sports Exerc 28:1327-1330

Tardieu-Berger M, Thevenet D, Zouhal H, Prioux J (2004) Effects of active recovery between series on performance during an intermittent exercise model in young endurance athletes. Eur J Appl Physiol 93:145-152

Taylor H, Buskirk E, Henschel A (1955) Maximal oxygen intake as an objective measure of cardiorespiratory performance. $\mathrm{J}$ Appl Physiol 8:73-80

Wasserman K, Hansen JE, Sue DY, Whipp BJ, Casaburi R (1994) Principle of exercise testing and interpretation, 2nd edn. Lea and Febiger, Philadelphia, pp 126-127

Wenger HA, Bell GJ (1986) The interactions of intensity, frequency and duration of exercise training in altering cardiorespiratory fitness. Sports Med 3:346-356

Whipp B, Ward S, Wasserman K (1984) Ventilatory responses to exercise and their control in man. Am Rev Respir Dis 129(2pt2):S17-S20 